\title{
PREVALÊNCIA DE STREPTOCOCCUS SUIS SOROTIPO 2 EM TONSILAS DE SUÍNOS SADIOS EM IDADE DE ABATE NO ESTADO DE SANTA CATARINA
}

\section{(Prevalence of Streptococcus suis serotype 2 in tonsils of healthy slaughter pigs in southern Santa Catarina)}

\author{
LARA, A.C.1; MORES, M.A.Z.1; SONCINI, R.A. ${ }^{2}$; ALBERTON, G.C. ${ }^{3}$ \\ 'Sadia S.A, \\ ${ }^{2}$ Médico Veterinário Autônomo, \\ ${ }^{3}$ Departamento de Medicina Veterinária - UFPR
}

\begin{abstract}
RESUMO - Pesquisou-se Streptococcus suis sorotipo 2 em tonsilas de suínos sadios em idade de abate. Em um matadouro de suínos localizado no oeste do Estado de Santa Catarina - Brasil foram amostrados 34 lotes de suínos provenientes de granjas de engorda da região. De cada lote foram colhidas amostras de tonsilas de 10 suínos. As amostras foram processadas em grupos de três, de maneira que para cada lote obtiveram-se resultados de três pools. No laboratório as amostras foram submetidas ao isolamento bacteriano e provas bioquímicas. Dos 34 lotes analisados, 19 apresentaram pelo menos uma amostra positiva para o Streptococcus suis sorotipo 2, perfazendo uma prevalência de $55,88 \%$. A prevalência dentro dos lotes positivos variou entre 10 e $70 \%$, com uma média de $27,36 \%$. Estes resultados indicam que suínos em idade de abate são portadores sadios do $S$. suis sorotipo 2 nas tonsilas, sendo alta a prevalência de lotes positivos.
\end{abstract}

Palavras-Chave: Streptococcus suis; suínos; portadores; tonsilas.

ABSTRACT: Tonsils from healthy pigs of slaughter age were removed to isolate Streptococcus suis serotype 2. Thirty-four fattening pig herds were sampled from a pig slaughterhouse located in Santa Catarina state, Brazil. Tonsils from 10 pigs were taken from each of the herds and the tonsils pooled. Samples were processed in groups of 3 in a manner that from each herd results were obtained from 3 pools. At the laboratory, samples were processed using standard bacteriologic isolation methods. From the 34 herds analyzed, 19 (55.88\%) were positive for at least one positive sample for $S$. suis serotype 2. Prevalence for positive herds ranged from 10 to $70 \%$, with a mean of $27.36 \%$. Results demonstrate the high number of infected tonsils in herds of pigs at the slaughter age, serving as healthy carriers for S. suis serotype in Southern Brazil.
Key words: Streptococcus suis; swine; healthy carrier state; tonsils.

\section{INTRODUÇÃO}

O Streptococcus suis é uma bactéria Gram-positiva, de forma cocóide, anaeróbica facultativa, que é responsável por grandes prejuízos à suinocultura mundial, podendo causar septicemia, meningite, artrite, endocardite, polisserosite e pneumonia em suínos (GOTTSCHALK e SEGURA, 2000).

$A$ infecção pelo $S$. suis em humanos ocorre de forma esporádica, geralmente afetando pessoas em contato com suínos ou que manipulam produtos cárneos de origem suína. A infecção em humanos causa meningite, podendo causar a morte dos indivíduos infectados ou deixar graves seqüelas. Estudos recentes indicam a possível transmissão deste agente dos suínos para os humanos (WONGSAWAN et al., 2006), notabilizando-se neste aspecto o surto desta enfermidade, ocorrido no ano de 2005, na Província de Sichuan na China, no qual 500 suínos e 38 pessoas morreram (JIN et al., 2006). Por outro lado, existem relatos de infecção em humanos que não tinham contato com suínos (HIDALGO et al., 2007) e, também, trabalhos demonstrando que a maioria das cepas que causam infecção em humanos, possui diferença genética daquelas isoladas de suínos enfermos (WONGSAWAN et al. 2006).

Desde que o $S$. suis foi identificado em 1987, já foram reconhecidos 35 distintos sorotipos. Dentre estes, o sorotipo 2 tem sido o mais comumente isolado de animais doentes, embora outros sorotipos possam também estar associados a casos graves de infecções (CLOUTIER et al., 2003). No Brasil, o sorotipo 2 também tem sido o mais isolado de suínos enfermos (COSTA et al., 2005)

Em condições naturais, muitos suínos são carreadores sadios de variados sorotipos de $S$. suis, tanto na cavidade nasal quanto nas tonsilas, sendo 
Prevalência de streptococcus suis sorotipo 2 em tonsilas de suínos sadios em idade de abate no estado de Santa Catarina

considerados importantes na epidemiologia e transmissão do agente (QUINN et al., 2005).

No Reino Unido foi estudada a prevalência de suínos carreadores de $S$. suis sorotipo 2 nas tonsilas em quatro rebanhos. O percentual de carreadores encontrado nos diferentes grupos de idade variou de zero a $80 \%$, sendo mais alto em animais entre quatro e 10 semanas (CLIFTON-HADLEY et al., 1984).

MARTINS et al. (1985) realizaram um estudo epidemiológico da meningite estreptocócica em 33 granjas de suínos no Estado de Santa Catarina. Os resultados demonstraram que a doença era enzoótica, com ocorrência esporádica. Os animais eram afetados do nascimento ao abate, com maior freqüência no período de crescimento.

A elevada prevalência de portadores sadios do S. suis tipo 2 favorece a disseminação do agente. A transmissão horizontal ocorre pelo contato nasonasal, sendo que a transmissão aérea ocorre a uma distância de até $40 \mathrm{~cm}$, sem a necessidade do contato direto entre os animais (BERTELHOT-HÉRAUT et al., 2001). Além da transmissão aerógena, a vertical também já foi descrita. A fêmea portadora desta bactéria no trato reprodutivo pode contaminar o leitão durante ou logo após o parto (CLOUTIER et al., 2003).

O presente trabalho teve como objetivo avaliar a prevalência do Streptococcus suis sorotipo 2 nas tonsilas de suínos clinicamente sadios em idade de abate, provenientes de rebanhos do meio-oeste do estado de Santa Catarina.

\section{MATERIAL E MÉTODO}

Em um matadouro de suínos localizado no oeste catarinense, foram colhidas amostras de tonsilas de 34 lotes de suínos clinicamente sadios, provenientes de granjas de terminação da região, sem sinais clínicos de infecção pelo $S$. suis sorotipo 2. A colheita foi realizada na sala de evisceração das carcaças. De cada lote foram colhidas aleatoriamente tonsilas de 10 animais, totalizando assim 340 animais amostrados. As tonsilas, uma vez colhidas, foram armazenadas individualmente em sacos plásticos e encaminhadas em caixa isotérmica com gelo ao laboratório, para o devido processamento bacteriológico.

As tonsilas foram processadas em grupos, de maneira que para cada lote de suínos obtiveramse três pools distintos: o primeiro e o segundo pool composto por amostras de tonsilas de três suínos, e o terceiro por amostras de quatro.

No laboratório, após a retirada dos excessos de gordura, as amostras foram embebidas em álcool $70^{\circ} \mathrm{GL}$ e flambadas. Após, foram recortadas com tesoura, colocadas em sacos plásticos estéreis contendo $10 \mathrm{~mL}$ de solução salina a $0,85 \%$ e processadas em Stomacher $\circledR^{\circledR}$. A suspensão foi inoculada em placas de Agar nutriente com $5 \%$ de sangue ovino e incubadas a $37^{\circ} \mathrm{C}$ por 24 horas.

As colônias bacterianas com características morfológicas de $S$. suis ( $\alpha$ hemólise, puntiforme de coloração cinza, lisas, com 0,3 a 0,9 mm de diâmetro) foram repicadas em placas de Agar nutriente com $5 \%$ de sangue ovino e incubadas a $37^{\circ} \mathrm{C}$ por 24 horas, de modo a obterem-se colônias puras para a realização das provas bioquímicas.

Como triagens, realizaram-se as provas de coloração de Gram, da catalase, e fermentação da rafinose. Colônias que na coloração de Gram apresentaram-se como cocos Gram positivos em cadeias curtas, com presença de formas diplocócicas, negativas na prova de catalase e fermentadoras de rafinose foram submetidas a provas bioquímicas complementares com o uso do kit comercial Api 20 Strep (BioMérieux®) para a diferenciação de espécies do gênero Streptococcus.

\section{RESULTADOS E DISCUSSÃO}

Dos 34 lotes analisados, 19 mostraram-se positivos para o $S$. suis tipo 2, perfazendo uma prevalência de $55,88 \%$ de lotes portadores. A prevalência de animais positivos dentro dos lotes analisados variou entre 10 a $70 \%$, com a média de $27,36 \%$.

A prevalência de $55,88 \%$ encontrada entre os 34 lotes analisados foi superior à observada em estudo realizado no Canadá, onde se demonstrou a presença do sorotipo 2 em apenas $12 \%$ de rebanhos sadios (BRISEBOIS et al., 1990). Entretanto, também no Canadá, MONTERFLORES et al. (1993) encontraram resultados semelhantes aos deste estudo, onde $42 \%$ dos rebanhos estavam infectados, sem, contudo apresentarem os sinais clínicos. Autores Britânicos também encontraram resultados semelhantes, em quatro rebanhos analisados, que não apresentavam sinais clínicos, sendo a metade positivos para $S$. suis tipo 2 (CLIFTON-HADLEY et al., 1984).

A alta prevalência de portadores sadios se deve pela facilidade com que o $S$. suis é transmitido da porca para os leitões, sendo que esta bactéria pode contaminar os leitões já no momento do parto, uma vez que este agente pode ser encontrado no trato respiratório superior e no trato genital (CLOUTIER et al., 2003).

Os resultados de prevalência dentro dos lotes ratificam observações de outros autores que encontraram índices muito semelhantes de prevalência de $S$. suis tipo 2 em animais sadios em idade de abate, provenientes do Rio Grande do Sul e Itália, 
por exames bacteriológicos (BARCELLOS et al., 1995 e SCANZIANI et al., 1993). Em contrapartida, FOCCOLI et al. (1993) realizaram um estudo semelhante, porém utilizando animais refugos, e encontraram uma prevalência de $69 \%$ de suínos carreadores do S.suis.

Os resultados deste trabalho indicaram a existência de alta prevalência de suínos sadios em idade de abate portadores de $S$. suis sorotipo 2. Entretanto, há que se considerar a existência de variações de patogenicidade dentro de um mesmo sorotipo, como demonstrado por WISSELINK et al. XX, (2000) que observaram que cepas de $S$. suis tipo 2 produtoras de fatores de patogenicidade como muramidaserelease-protein (MRP) e o Fator Extracelular Protéico $(E F)$ são isoladas principalmente de suínos doentes, enquanto que as cepas negativas para estes dois fatores são isoladas principalmente de suínos sadios. Por outro lado, há que se considerar que não existe na atualidade conhecimento científico suficiente para explicar de que maneira o $S$. suis expressa sua patogenicidade e, de que forma os fatores de patogenicidade atualmente identificados podem contribuir com a virulência do agente (GOTTSCHALK e SEGURA, 2000). Deste modo, ainda permanece obscuro o risco sanitário para os suínos e para o homem que as cepas de $S$. suis sorotipo 2 isoladas de animais sadios oferecem.

$O$ fato de que os rebanhos amostrados no presente estudo não apresentavam problemas clínicos relacionados ao $S$. suis sorotipo 2 , evidenciam a necessidade da realização de novas pesquisas que esclareçam a importância dos portadores sadios deste agente na cadeia epidemiológica das doenças por ele provocadas.

\section{CONCLUSÕES}

Observou-se uma alta prevalência de suínos em idade de abate, portadores sadios de $S$. suis sorotipo 2, em granjas de terminação da região Oeste de Santa Catarina.

\section{REFERÊNCIAS}

BARCELLOS,D.; BOROWSKI,S.M.; OLIVEIRA,S.J. Infecção de suínos pelo Streptococcus suis tipo II no Rio Grande do Sul: Pesquisa de portadores pelo exame bacteriológico de amígdalas coletadas em frigoríficos. Arquivos da Faculdade de Veterinária UFRGS, v.23, p.101-106, 1995.
BERTHELOT-HÉRAUT,F.; GOTTSCHALK, M.; LABBÉ, A.; CARILET,R.; KOBISCH, M. Experimental airborne transmission Streptococcus suis capsular type 2 in pigs. Veterinary Microbiology, v.82, p.6980, 2001.

BRISEBOIS,L.M.; CHARLEBOIS,R.; HIGGINS,R.; NADEAU,M. Prevalence of Streptococcus suis in four to eight week old clinically healthy piglets. Canadian Journal of Veterinary Research, v.54, p.174-177, 1990.

CLIFTON-HADLEY,F.A.;ALEXANDER, T.J.L.; ENRIGHT, M.R.; GUISE, J. Monitoring herds for Streptococcus suis type 2 by sampling tonsils of slaughter pigs. The Veterinary Record, v.115, p.562-564, 1984.

CLOUTIER,G.; D'ALLAIRE, S.; MARTINEZ, G.; SURPRENANT,C.; LACOUTURE,S.; GOTTSCHALK, M. Epidemiology of Streptococcus suis serotype 5 infection in a pig herd with and without clinical disease. Veterinary Microbiology, v.97, p.135-151, 2003.

COSTA, A.T.R;LOBATO,FCF;ABREU,VLV;ASSIS, RA; REIS,R;UZAL,FA. Sorotyping and evaluation of the virulence in mice of Streptococcus suis strains isolated from diseased pigs. Revista do Instituto de Medicina Tropical de São Paulo, v. 47, n. 2, p. 113-115, 2005.

FOCCOLI,E.; SALA,V.; VIGO,D.; PERSICO,F. Sulle localizzazioni di Streptococcus suis tipo 2 in suini con evidente ritardo di crescita (scarti di produzione). In: Meeting Annuale della Societa Italiana di Patologia ed Allevamento dei Suini, XIX. 1992, Parma, Anais... Parma: Societa Italiana di Patologia ed Allevamento dei Suini, 1993, p.291-300.

GOTTSCHALK, M., SEGURA, M., The pathogenesis of the meningitis caused by Streptococcus suis: the unresolved questions. Veterinary Microbiology, v. 76, p. 259-272, 2000.

HIDALGO,A.;ROPERO,F;PALACIOS,R;GARCIA,V; SANTOS,J. Meningitis due to Streptococcus suis with no contact with pigs or porcine products. Journal of Infection. p. 01, 2007.

JIN, JML; ZHANG, A.; KANG,CAO; SHI,J; ZHENG,PEI; TU,J; WU,BIN; CHEN,HC. Detection of antibodies against Streptococcus suis capsular type 2 in China using an indirect elisa. In: INTERNATIONAL 
Prevalência de streptococcus suis sorotipo 2 em tonsilas de suínos sadios em idade de abate no estado de Santa Catarina

PIG VETERINARY SOCIETY CONGRESS, XIX. 2006, Copenhagen, Proceedings...Copenhagen: IPVS, 2006, p. 263.

MARTINS,V.M.V.; RIET-CORREA,F.;BRITO,M.A.V.P.; SONCINI,R.P.; BRITO,J.R. F.; PIFFER,I.P.; ORLANDI, J.J. Meningite estreptocócica dos suínos no Estado de Santa Catarina. Pesquisa Veterinária Brasileira, v.5, n.1, p.27-35, 1985.

MONTERFLORES,J.L.; HIGGINS,R.; D'ALLAIRE, S.; CHARETTE,R.; BOUDREAU,M.; GOTTSCHALK,M. Distribution of the different capsular types of Streptococcus suis in nineteen swine nurseries. Canadian Veterinary Journal, v.34, p.170-171, 1993.

QUINN,P.J.; MARKEY,B.K.; CARTER,M.E.; DONNELLY,W.J.; LEONARD,F.C. Estreptococos. In:_ Microbiologia veterinária e doenças infecciosas. Porto Alegre: Artmed, 2005, p. 61-66.

SCANZIANI,E.; TREVES,E.; GIUSTI, A.M.; SALA,V.; FOCCOLI, E., COLOMBO,A. Identificazione immunoistochimica di Streptococcus suis tipo 2 in tonsille di suino. Obiettivi e Documenti Veterinari., v.14, n.11, p.51-54, 1993.

WISSELINK,HJ; SMITH,HE; STOCKHOFEZURWIEDEN,N; PEPERKAMP,K; VECHT,U. Distribution of capsular types and production of maramidase-released protein (MRP) and extracellular factor (EF) of Streptococcus suis strains isolated from diseased pigs in seven European countries. Veterinary Microbiology, v. 74, p. 237-248, 2000.

WONGSAWAN,K.; TAKENAMI, N .; PRUKSAKORN, S.; FONGCOM, A.; GOOTTSCHALK,M.; SUPJATURA,V.; TAKAI,S.; THARAVICHITKUL,P. Genetic diversity of Streptococcus suis isolated from pigs and humans in Chiang Mai and Lamphun province, Thailand, IN: Lancefield International Symposium on Streptococci and Streptococcal Diseases, XVI., 2005, Palm Cove, Proceedings..., Palm Cove : International Congress Series, v.1289, 2006, p.151-154. Disponível em: $:<$ http://www.scielo.br/> Acesso em 05 de maio de 2006.

Recebido para publicação: $\quad$ 01/08/2006 Aprovado:

$09 / 07 / 2007$ 